\title{
Characteristics of self-perception and meaningfulness of life of professionally determined students
}

\author{
Liubov Ryumshina* \\ Southern Federal University, 344711 Rostov-on-Don, Russia
}

\begin{abstract}
Professional identity is the embodiment of life's meanings and values of the individual. Its fulfillment rests in its basis on the person's perception of oneself and attitude toward oneself. Even choosing a certain profession and studying it, the students still have a choice of further professional identity. In consideration of the foregoing,the purpose of the work is to study the characteristics of self-perception and meaningful orientations of professionally determined students. Methodological tools of the study were Maslow's self-actualization scales, a test of meaningful orientations, a questionnaire aimed at identifying professionally determined and not determined students. 96 students took part in the study. The results showed that professionally determined students have a tendency to a fairly high general meaningfulness of life. They feel that they can manage their own lives and have a sufficient level of responsibility. The self-esteem of the professionally determined students is related to the positive perception of their life in each of its periods. In general, professionally determined students have many characteristics similar to professionally not determined students, but they also have specific features. They are manifested in the interconnection between meaningful orientations, self-esteem and self-acceptance of professionally determined and not determined students.
\end{abstract}

\section{Introduction}

The issues of self-attitude [1-2], and self-awareness[3-6], as a person's awareness of oneself being different from other subjects and the world in general, person's beliefs of oneself, formation of the mental image of "Self" and the system of meaningful orientations [7-8], have long been of interest in psychology [9-10, etc.]. Particular attention to these personal phenomena is paid in existential-humanistic psychology, a direction that is devoted to the study of issues of self-knowledge and self-awareness [2, 11-14, etc.].

Another topic that psychologist spay considerable attention to, and whole separate branch of psychology is devoted to - the issue of life's journey of the person [15, etc.] and life choice [16,etc.]. Currently, one of the most important life choices that any person faces is professional choice, and its study is becoming more and more relevant every year. It is

\footnotetext{
* Corresponding author: ryumshina@sfedu.ru
} 
professional self-determination that becomes the embodiment of life meanings and values of the person, and is one of the ways of their implementation. At the same time, making a professional choice, as well as any other life choice, rests in its basis on the person's perception of oneself and attitude to oneself [17-18]. Thus, the study of the phenomena of self-perception and meaningful orientations with regard to professional choice may not only explain the mechanisms for making such decisions, but also provide a key on how to increase their effectiveness through the development of these personal phenomena.

All of the above is true for students. Even when choosing a certain profession and studying it the students, nevertheless, still have a choice of further professional selfdetermination. However, only a conscious and independent professional choice rests on the true values and goals of the student [19]. However, as practice shows, often this choice is made under the influence of the reference group of the student, his closest associates or other authoritative sources for him. Also, especially at early study years, students often have unrealistic ideas about the future profession; the lack of real experience does not allow them to compare the requirements of a particular position with their capabilities and desires, so the awareness of their professional self-determination is not obvious.

\section{Purpose}

In consideration of the foregoing, the purpose of the work is to study the characteristics of self-perception and meaningful orientations of professionally determined students.

\section{Methods}

Methodological tools of the study were Maslow's self-actualization scales, a test of meaningful orientations (D.A. Leontiev), a questionnaire aimed at identifying professionally determinedand not determinedstudents.

96 students of the second, third and fourth years took part in the study.

\section{Results}

\subsection{First stage of the study}

The study included the pilot and main stages.

The purpose of the pilot study was a preliminary study of the characteristics of selfacceptance and self-esteem of students who have determined and who have not determined their professional choice. 30 third-year students took part in this study. The SAT questionnaire and the author's methodology were used. The results were processed using descriptive statistics.

The goal of the main stage was to study the indicators of self-acceptance, self-esteem and meaningful orientations among professionally determined students. A total of 66 people participated in the study (33 second-year students and 33 fourth-year students). The SAT questionnaire, meaningful orientations test and the author's methodology were used. We used descriptive statistics, Mann-Whitney U-test, Spearman correlation analysisas methods of mathematical processing.

The results of the pilot study showed that in accordance with the self-esteem and selfacceptance indicators, a group of professionally determined students has more medium and high indicators and less low indicators than students who have not yet made a professional choice. Nevertheless, it is worth considering that the third year students are not exactlyon the threshold of professional choice. In light of this, we considered it necessary to study the 
students closest to the direct fulfillment of the professional choice - fourth-year students. As a control group, we took students, at first glance, more distant from professional choice, but, at the same time, already having a certain, though not completely clear idea of the future profession, - second-year students.

The results of the carried out study made it possible to identify professionally determined and undetermined students both at the second and fourth years of studying. So, in the second year, 20 professionally determined students were identified, which is $60.6 \%$ of their total number, and 11 undetermined students, which is $33.3 \%$, respectively. As for the fourth year, 26 determined students were identified $-78.8 \%$ of the total number and 7 undetermined students $-21.2 \%$, respectively. Thus, it turned out that the presence of professionally determined and undetermined students practically does not depend on the study year, including the formed idea of the future profession. In this regard, further analysis was focused on the comparison of two groups of respondents (professionally determined and undetermined) regardless of the year of their study.

\section{2. Second stage of the study}

We assumed that professionally determined students are characterized by a higher level of self-acceptance, self-esteem and meaningfulness of life than the professionally undetermined respondents, and there are differences in the interrelations between these indicators among groups of students who have and have not made a professional choice. However, the results of the study showed no difference in the indicators of self-acceptance and self-esteem between professionally determined and undetermined students $(p \geq 0,05)$. As can be seen from Figures 1 and 2, the expression of self-esteem for professionally determined and undetermined students is almost the same.

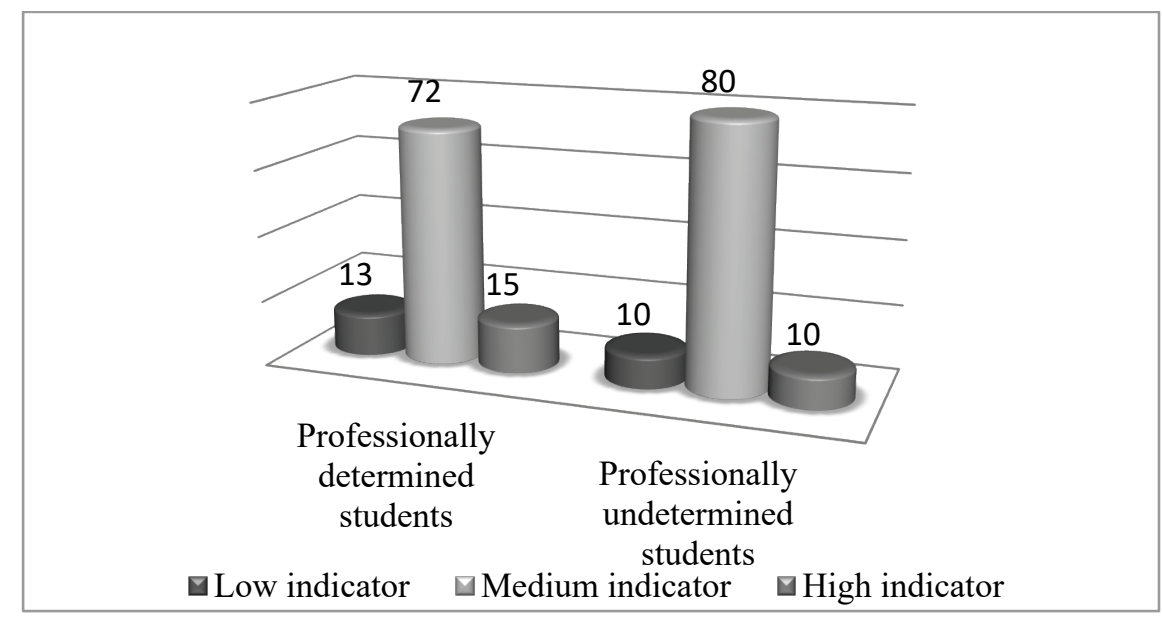

Fig. 1. The expression of self-esteem of professionally determined and undetermined students 


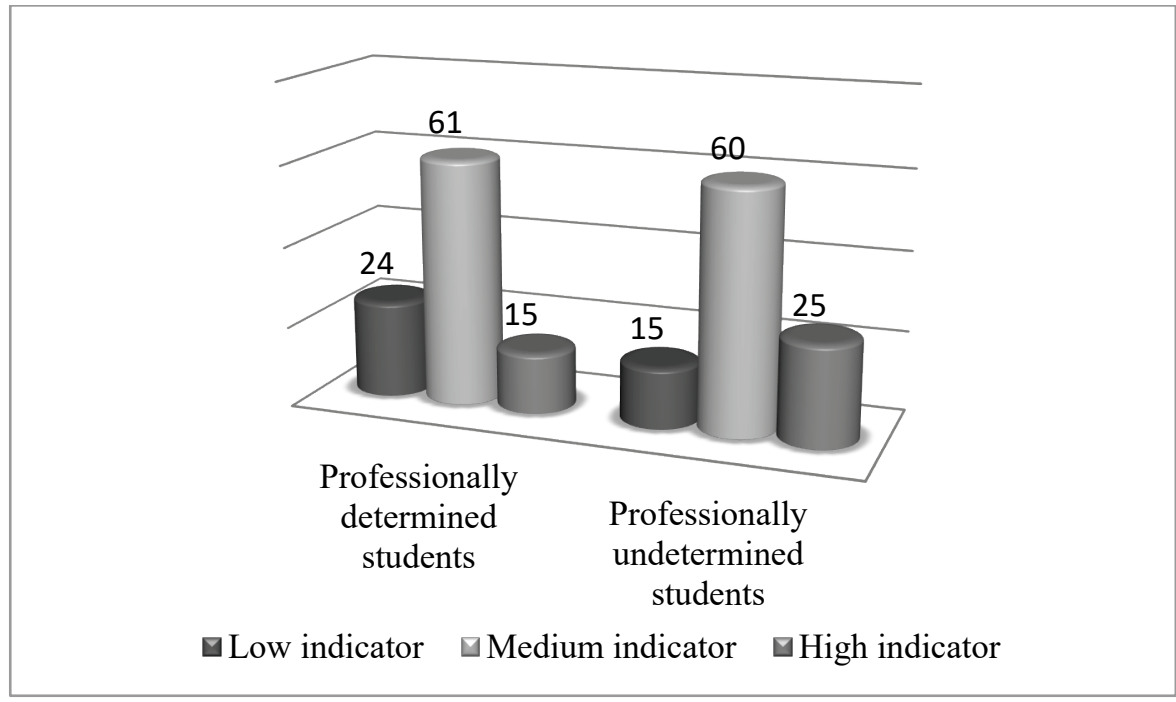

Fig. 2. The expression of self-acceptance of professionally determined and undetermined students

In our opinion, this is due to the fact that these phenomena are determined by other parameters that were not considered by us in this study. In particular, they can be interrelated with the student's achievements in other (not academic and non-professional) areas of life that are relevant to him. Nevertheless, differences between the professionally determined and undetermined students were found in the number of low and high results according to the indicators of the general meaningfulness of life, which consists of satisfaction with each of the periods of one's life and a sense of one's ability to control it ( $p$ $\geq 0,05$ ) (Figure 3).

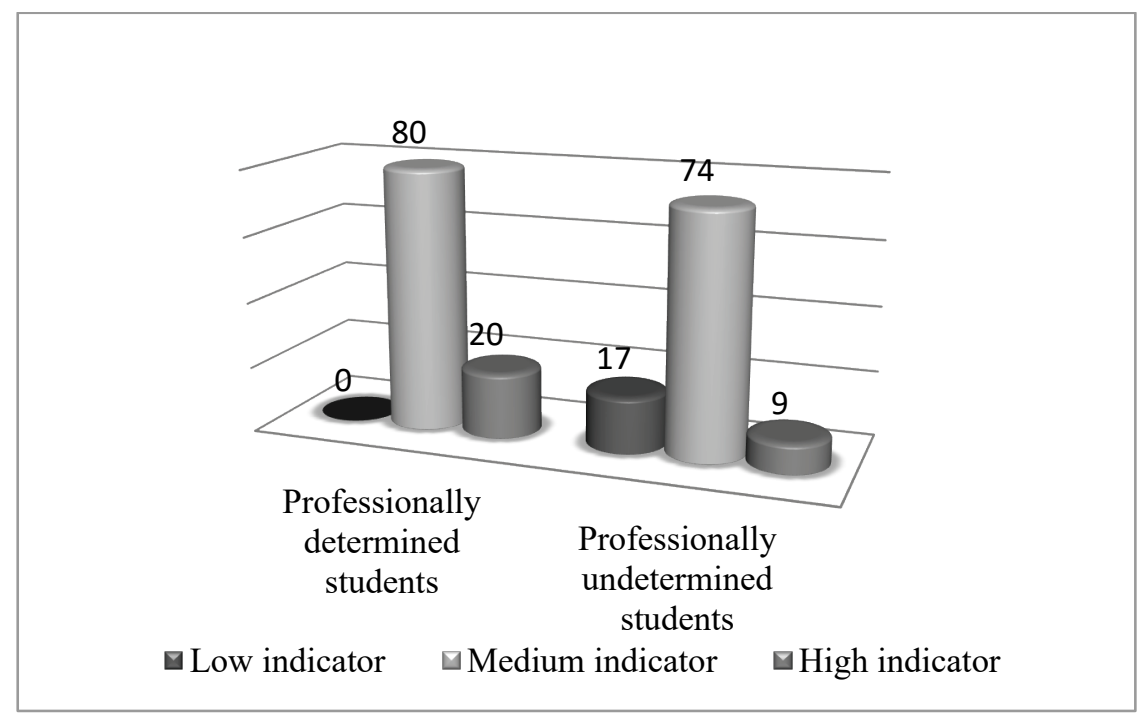

Fig. 3. The expression of the general meaningfulness of life of professionally determined and undeterminedstudents 
This indicates the tendency of professionally determined students to a higher, than the students that still have not made their professional choice, subjective assessment of the significance of their lives, a greater focus on the future, satisfaction with the present and the past, a belief in their ability to form their unique way of life.

Along with this, empirical research has allowed us to identify the differences in the interrelations between self-acceptance, self-esteem and the meaningful orientations of professionally determined and undetermined students. Thus, it was found that the formation of self-esteem for professionally determined students is closely related to the awareness of the significance of all periods of their life - present, past and future (which are also very closely interrelated), self-acceptance, on the contrary, is not related with it in a meaningful way, in addition, it often relies on the positive experience of past self-actualization. The sense of the ability to control one's life also intersects with satisfaction with each of life's stages and the active participation of a person in them, and the most significant period for the formation of this feeling is a real piece of life. The obtained results allowed us to identify certain features inherent to professionally determined students, and to compile their psychological portrait.

Thus, it can be stated that professionally determined students in most cases feel strong enough to manage their own lives and have a sufficient level of responsibility for this. Accordingly, they also have the conviction that a person can build his or her life path in accordance with one's goals and values, which is what they implement in their life.

Self-esteem of the professionally determined students is associated with a positive perception of their life in each of its periods - past, present and future. In the perception of professionally determined students, past life span, current stage and prospects for the future are closely interrelated, and, perhaps, are mutually reinforcing each other. The past, perceived as a productive and meaningful stage of life, is a solid base for achievements in the present period of life, serves as a source of self-confidence and a positive image of the Self on which students can build their current life, define goals for the future and strive for them. Perhaps, the existing goals give the direction and vector of motion to the present life period, a sense of opportunity. It can be assumed with a high degree of certainty that the meaning of life of professionally determined students generally gives all three temporary life periods in close relationship. Accordingly, the lack of a positive perception of at least one period of life (underestimation of past experience, a feeling of emotional poverty of the present or goals corresponding to the values and interests of the person) can significantly reduce the overall level of sense of meaning and satisfaction with life.

The greatest correlation of the feeling of a strong personality among professionally determined students can be traced with the present period. This suggests that, despite the importance of each of the life stages for the formation of the feeling "I am the master of my life," it is the present period that is a key for professionally determined students, and the past and the future are the prop and stay. In other words, the ability to build your life in accordance with your goals, values and desires is formed most in the course of current events, here and now.

Unlike self-esteem, which closely intersects with satisfaction with all periods of one's life and the ability to actively participate in its construction, the self-acceptance of professionally determined students is practically independent of these parameters. An exception is the reliance on the previous self-actualization, which, apparently, plays a role in forming a sense of self-acceptance for professionally determined students. It can be assumed that previous successes lead to a positive perception of oneself by the person, which, in turn, helps to achieve new successes. 


\section{Conclusion}

So, the conducted research partially confirmed the first hypothesis and fully confirmed the second one. Despite the fact that professionally determined students have many characteristics similar to those of professionally undetermined students (a similar level of self-acceptance and self-esteem), it is possible to identify specific characteristics for them, which made it possible to compile their psychological portrait.

The tasks of further study can be the search for and identification of parameters and factors affecting the professional self-determination itself.

\section{References}

1. R. Burns, Self-Concept Development and Education (Cassell, London, 1992)

2.V. Frankl, Man's Search for Meaning. An Introduction to Logotherapy (Beacon and Random House / Rider, Boston, 2004)

3. E. Fromm, To Have or to Be (Open Road Media, New York, 2005)

4. J. Ferris, Scientific American Mind. 23 (5), 28-29 (2012)

5. J. Baggini. The Ego Trick: What Does It Mean To Be You? (Granta Books, London, 2011)

6. C. Gatti. Eth.Ecol. \& Evol. 28 (2), 232-240 (2016)

7. D. Leontiev, Psychology of meaning: the nature, structure and dynamics of the sense of reality (Smysl, Moscow, 2007)

8. D. Myers, Social Psychology.5th Canadian edition (Mcgraw-Hill Ryerson Limited, Canada, 2012)

9. V. Salakhova, M. Tkhugo, L. Shalamova, M. Polevaya, E. Pozharskaya, Man in India. 97 (9), 121-130 (2017)

10. J. Laird, Feelings: The Perceptions of Self (Oxford University Press, New York, 2007)

11. C. Rogers, On Becoming a Person (Constable, 2004)

12. S. Kreitler, Meanings of Meaningfulness of Life (Logoth. Exis.Anal, 2016)

13. A. Pattakos, E. Dundon, J. Construc. Psych, 1-8 (2016)

14. L. Ryumshina. SGEM. Bulgaria. 3, 369-374 (2014)

15. J. Spencer, Life-Changing Events (Alive After Academia, 2019)

16. M. Huber, Psychology for a Better World: A Cross-Cultural Anthology of Emotional Well-Being, (Cambridge Scholars Publishing, Cambridge, 2019)

17. D. Miroshkin, T. Shulga, M. Melamud, V. Maslova, O. Lazareva, A. Vrublevskiy, I. Kochetkov. Eur. J. Anal. Ch. 13(1b) (2018)

18. R. Robak, A. Ward \& K. Ostolaza. Psych. 7, 337-344 (2005)

19. N. Meshcheriakova. Sociodyn. 3, 167-174 (2016) 